\title{
Practical research on the teaching of Optical Design
}

\section{Changjiang Fan, Zhijun Ren, Chaofu Ying, Baojin Peng}

Changjiang Fan, Zhijun Ren, Chaofu Ying, Baojin Peng, "Practical research on the teaching of Optical Design," Proc. SPIE 10452, 14th Conference on Education and Training in Optics and Photonics: ETOP 2017, 104524F (16 August 2017); doi: 10.1117/12.2267235

SDIE Event: 14th Conference on Education and Training in Optics and Photonics, ETOP 2017, 2017, Hangzhou, China 


\title{
Practical Research on the Teaching of Optical Design Fan changjiang ${ }^{a}$ Ren zhijun ${ }^{a}$ Ying chaofu ${ }^{a}$ Peng baojin ${ }^{a}$ \\ a the Department of optical engineering, Zhejiang Normal University
}

\begin{abstract}
Optical design, together with applied optics, forms a complete system from basic theory to application theory, and it plays a very important role in professional education. In order to improve senior undergraduates' understanding of optical design, this course is divided into three parts: theoretical knowledge, software design and product processing. Through learning theoretical knowledge, students can master the aberration theory and the design principles of typical optical system. By using ZEMAX(an imaging design software), TRACEPRO(a lighting optical design software), SOLIDWORKS or PROE( mechanical design software), student can establish a complete model of optical system. Student can use carving machine located in lab or cooperative units to process the model. Through the above three parts, student can learn necessary practical knowledge and get improved in their learning and analysis abilities, thus they can also get enough practice to prompt their creative abilities, then they could gradually change from scientific theory learners to an Optics Engineers.
\end{abstract}

Keywords: optical design, Zemax, Tracepro

\section{INTRODUCTION}

'Optical Design' is an important professional course about Optoelectronic Information Science and Technology, which mainly covers imaging theory of the ideal optical system, the structural principle of the typical optical system and aberration theory. Through studying the course, students can systematically master the aberration theory, the most commonly used optical system design methods, and understand the development direction of modern optical design. Through theoretical course study, the students can master the theoretical optical design knowledge, through the experimental course, students can deep understanding the theoretical knowledge and master software operation about optical design, through the extracurricular design practice about some optical system, students can get experience about optical design. The following are detailed analysis about the three parts.

\section{THE TEACHING OF THEORETICAL KNOWLEDGE}

\subsection{Teaching Content}

The contents of optical design include Gaussian optics, aberration theory, the typical optical system, computer automatic optimization method, optical system tolerance analysis and the mapping of optical component. In the teaching process, according to the actual situation, firstly review the 'geometric optics' part, secondly learn the primary aberration theory, omitted the typical optical components (telescope, microscopic objective lens), thirdly learn LED lighting for increasing the ability of designing practical optical system, understand the non-imaging optics in the lighting system applications and hot spots about lighting research. This kind of modification makes the teaching content more prominent and actual requirements of modern optical design.

\subsection{Teaching Methods}

Detailed explaining the basic concept, reduce the derivation of complex formulas. For example, in the teaching process of aberration seidels number, explain the physical meaning and its application of each aberration seidels number in the formula, do not introduce how to derive aberration seidels number. 
We emphasize the student's dominant position. There are various scientific and technological innovation activities every year in our college, we encourage students to declare the projects using this course knowledge. In the past five years, every year students obtain all kinds of scientific and technological innovation projects, which drive a group of students to study this course deeply. T stimulate students' enthusiasm for learning this course, such as the study of 'optical path calculation of the near-axis light', students discuss together, calculated according the ray tracing of the paraxial optical path formula, derive the data and compare it with the table data in the textbook. Through discussion and hierarchical teaching, the course can meet the different learning ability and interest. The teaching process is not only a faithful implementation of the curriculum plan (program), but teachers and students develop and enrich the course, which truly become personalized creation process by teacher and students. The teaching process is always around the teaching objectives. Students have psychological dependence on the examination results, so we design a classroom training exercises, which can test the student's learning effect of the knowledge and promote all students to learn the basic knowledge and understanding of the content.

\subsection{Assessment Mechanisms}

The guiding ideology of the examination is to examine the comprehensive knowledge and ability. The experimental examination are divided into operating on the experimental and answering, Student can get 60 points when he can do the completed experimental steps, he can get other 10-20 points when he can answering the random theoretical knowledge, his experiment score is the sum of the two grades. After the experimental class, we set up the task of optical system design based on the hot spots of the optical system market and guide students to study the optical design.

For example, let the students study the principle of mobile phone camera, and then make the design goals for $40^{\circ}$ field angle, $1 / 3$ inch COMS receiver and 8 million pixels. If he can finish this project, he can get an extra 30 points. Though this, we can not only improve the student's experimental skills, but examine his overall quality.

Closed book exam. This part mainly tests the concept questions and thinking questions, the aim is to help students to understand and master the basic knowledge. This assessment method covers a more comprehensive knowledge, the results of the assessment will be more objective and reasonable. The assessment mechanisms can truly reflect the students' learning situation and ability level, it is conducive to conduct a comprehensive evaluation of the students' knowledge and ability.

\section{LECTURES ON EXPERIMENTAL COURSES}

In an attempt to reorientate the students' attitude towards Optics and their own degree studies, we set out a voluntary activity where we show them laboratory experiences represented by optical phenomena and applications. After this activity they were given a survey about different aspects related to their integration in their new studies and to their own activity. In this work, this activity is described as well as the results of the survey in order to establishing some of the factors that could improve the vocational orientation of the students and their adaptation to university studies. According to the former explanation, in the present work we have tried, in first place, to analyze the characteristics of the group that is acceding to the degree in Optics and Optometry and, in second place, to design an activity to try to improve the motivation of our students and to analyze if these types of activities achieve the goal for which they were created.

We selected ZEAMX, TRACEPRO and PROE as experimental software for the study of commercial optic design software which are widely used in the market. We designed 18 experimental courses base on the characteristics and the order of difficulty. The experimental courses of ZEMAX have 8, TRACEPRO have 3 and PROE have 7, for each experimental course there have about 10 theoretical problems. Students are required to practice in accordance with experimental tutorials, and then they are required to be able to practice experiments without looking at the tutorial and answer 2-4 questions. For example, in the study of 'large-sized light guide plate example', students can establish a mechanical model, set the optical parameters, analyze the parameters of the Photometry and Colorimetry using the software TRACEPRO. We also sort out some theoretical questions, which the students should answer. For example, 'Why should we establish the scales ', 'where is the luminous flux set', 'Why should we set a reflective cup at the back of the light bar', 'Why is the intensity distribution uneven?' and so on.

the experimental courses of ZEMAX are follows:

1 a singlet lens 
2 a double lens

3 a Newtonian telescope

4 Schmidt-Cassegrain with aspheric aligner

5 a multi-configuration laser beam expander

6 fold mirrors and coordinate breads

7 Achromatic single lens

8 the simulation of TIR lens
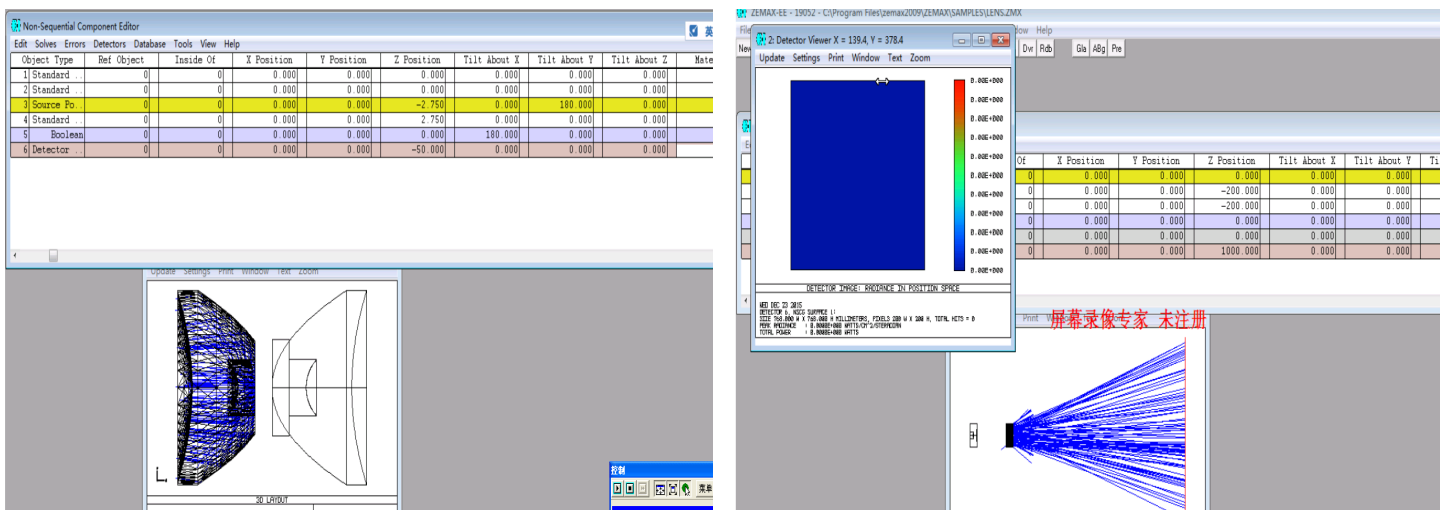

fig1 the simulation of TIR lens

the experimental courses of TRACEPRO are follows:

1 the simulation of LED package

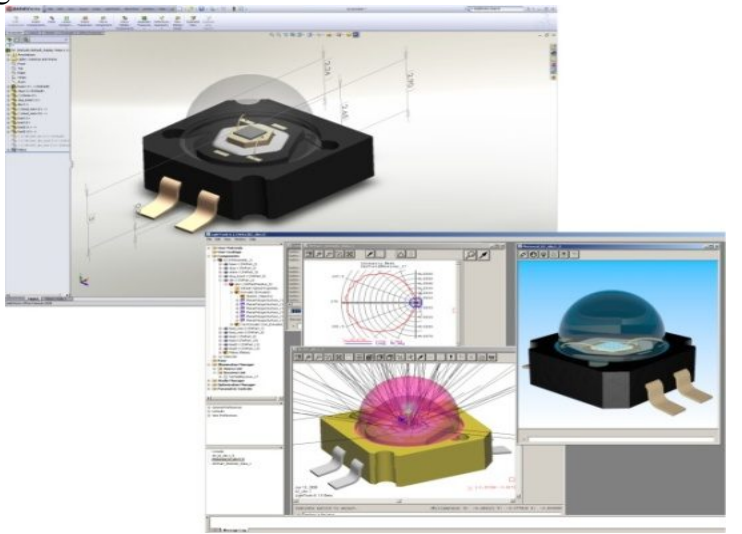

Fig2 the simulation of LED package

2 the simulation of LED backlight

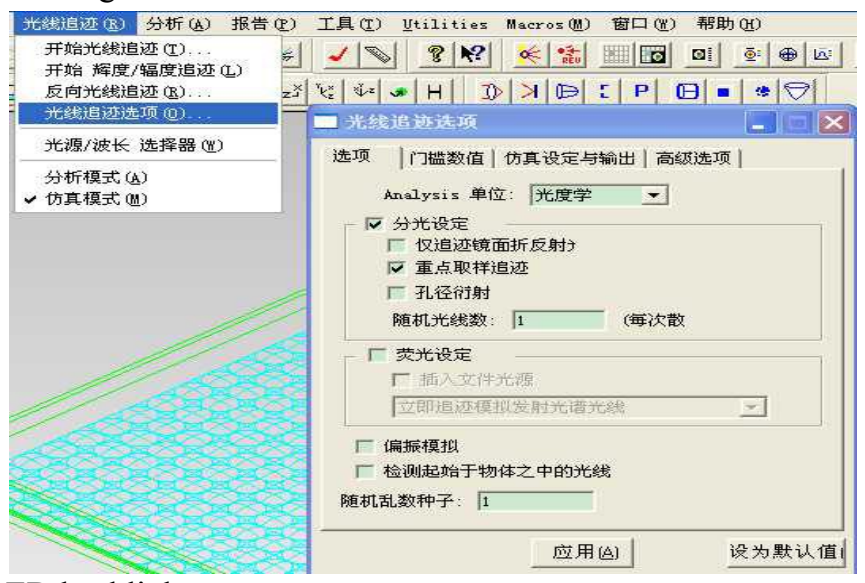

Fig3 the simulation of LED backlight 
3 the modeling of reflective cup

Fig4 the modeling of reflective cup

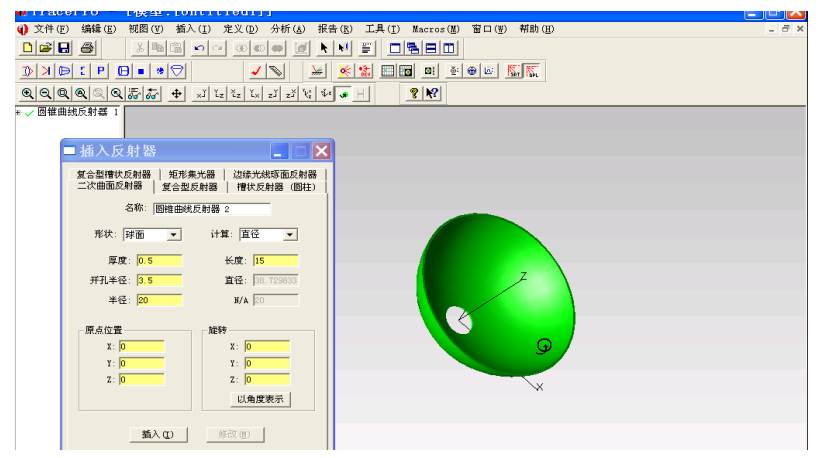

In the design of these experiences we took into account both the necessity to show in a clearway the basic principles and phenomena, and also to suggest their potential Engineer applications. Indeed, as we could see, it is the possibility of use of the optical technologies in their future professional fields that really encouraged the students interested; but our goal was not only they were able to appreciate the possibilities of practical use of the optics in engineering, we have also tried to make them understand, at least in a basic way, the optical fundamental concepts. We believe that the University engineering education should highlight its scientific basis and be not limited to training the students as future users of a particular technology. We want students to gain the idea that scientific knowledge, in principle very generic, are always at the root of any technological field.

\section{COURSE PRACTICE}

For the common optoelectronic products, such as LED light bar for car, the head up displayment (HUD) navigator, mobile phone camera, we set up design tasks for different optical system. Then we divide students into several groups, each group has an optical design task. Through this, we can let the students to get practical training.

The design of the automotive light bar using LED: the diameter is $5 \mathrm{~mm}$, the length is $500 \mathrm{~mm}$, the light source is $1601 \mathrm{~m}$, the efficiency of the light bar is greater than $50 \%$, and the uniformity of the Light bar is greater than $50 \%$.

The projection objective for the head up displayment (HUD): the parameters of the Display chip are 1/3 (16: 9) inch and 4 million pixels, the size of image pixel is $4 \mu \mathrm{m} 2$, the projection distance is $25 \mathrm{~cm}$, and the projection size is $10 \mathrm{~cm} * 20$ $\mathrm{cm}$. There is a mirror between the projective lens and the screen and the optical path have a inversion about $180^{\circ}$.

Iphone camera lens: the field of view is $40^{\circ}$, the size of the COMS is $1 / 3$ inch, the pixels have 8 million, and the size of pixels is $2.25 \mu \mathrm{m} 2$.

\section{CONCLUSION}

Through the practice of optical system design, students can master the size calculation of the optical system, the setting of the resolution and magnification. At the same time, students can master the operation of optical design software, the optimization techniques of the optical system in the software. They can accumulate the experience of optical system design through this experimental course.

We improved the teaching content through the adjustment of the curriculum structure, which benefit students to master the optical design theory knowledge. We explore the application of 'discussion learning' and 'hierarchical teaching' methods, Students can interact with teachers and actively use the knowledge of this course to declare national, provincial and school subjects. 
We explore the assessment mechanism which can stimulate student to independent learning and actively gain knowledge. Students can use the theoretical knowledge and experimental skills which they have learned to complete the design of the popular optical system. This course can cultivate the students' professional interest and improve the students' analytical ability and practice ability.

\section{REFERENCES}

[1] Rockland, R., Bloom, D. S., Carpinelli, J., Burr-Alexander, L., Hirsch, L. S. and Kimmel, H., "Advancing the"E" in K-12 STEM education," J. Technol. Stud., 36, 53-64, (2010).

[2] Orgill, M. and Crippen, K. J., "What's so big about being small? The interdisciplinary opportunity nanoscience,"The Science Teacher, 76, 41-48 (2009)

[3] O’Shea, D. C., "A survey of Lens Design Courses”, Proc. SPIE 3190, 75-81 (1997).

[4] Sasian, J. M., "Trends in Teaching Lens Design", Proc. SPIE 4588, 56-58 (2002)

[5] Bernero, B., "The Moire Effect in Teaching Physics", Phys. Teach. 27, 602-608 (1989).

[6] Richey, L., Stewart, B. and Peatross, J., "Creating and analyzing a mirage", Phys. Teach., 44, 460-464 (2006).

[7] Tarrant, J., Roorda, A., Wildsoet, C.F., "Determining the accommodative response from wavefront aberrations", JVis 10(5):4, 1-16, (2010). 